\title{
Predictors of Altered Sensorium at Admission in Children with Diabetic Ketoacidosis: Correspondence
}

\author{
Viktor Rosival
}

Received: 9 December 2014 / Accepted: 14 January 2015 /Published online: 26 February 2015

(C) Dr. K C Chaudhuri Foundation 2015

To the Editor: In the paper "Predictors of Altered Sensorium at Admission in Children with Diabetic Ketoacidosis" [1] there are some inaccuracies.

On page 1166, the authors write "... a multi-centric study by Glaser et al. showed that bicarbonate therapy is associated with a greater risk of cerebral edema" according to their reference 3 from 2001. However, in more recent papers the association between bicarbonate therapy and risk of cerebral edema is not mentioned [2,3]. Recent studies have not shown greater risk of cerebral edema as a consequence of bicarbonate therapy.

On the same page, the authors have explained the pathophysiological basis of the negative effects of low blood $\mathrm{pH}$ (high concentration of hydrogen ions $\mathrm{H}^{+}$) on the level of consciousness according to their references 8,9 , and 14 to 16 . However, surprisingly they conclude that "the causal association and exact pathophysiological mechanism of acidosis induced alteration in sensorium in DKA still remains unexplained ...". The most simple possibility to evaluate the validity of pathophysiologic principle of a disease is the resulting therapy. If low blood $\mathrm{pH}$ is the cause of coma in DKA, normalisation of the blood $\mathrm{pH}$ should be followed by recovery to full alertness. The study by Umpierrez et al. showed zero lethality of coma with bicarbonate therapy [4].

Conflict of Interest None.

Source of Funding None.

\section{References}

1. Chhapola V, Kanwal SK, Shafi OM, Kumar V. Predictors of altered sensorium at admission in children with diabetic ketoacidosis. Indian J Pediatr. 2014;81:1163-6.

2. Glaser N. Cerebral injury and cerebral edema in children with diabetic ketoacidosis: could cerebral ischemia and reperfusion injury be involved? Pediatr Diabetes. 2009;10:534-41.

3. Watts W, Edge JA. How can cerebral edema during treatment of diabetic ketoacidosis be avoided? Pediatr Diabetes. 2014;15:271-6.

4. Umpierrez GE, Kelly JP, Navarrete J, Casals MMC, Kitabchi AE. Hyperglycemic crises in urban blacks. Arch Intern Med. 1997;157: $669-75$.

\footnotetext{
V. Rosival $(\bowtie)$

SYNLAB Department of Laboratory Medicine, Dérer's Hospital, Limbová 5, SK-833 05 Bratislava, Slovakia, Europe

e-mail: rosivalv@hotmail.com
} 